\title{
Gastric Cancer: Applicability and Feasibility of Molecular and \\ Histological Classification in Clinical Practice
}

\author{
Esmeralda Celia Marginean ${ }^{1,2}$ \\ ${ }^{1}$ Baylor College of Medicine, ${ }^{2}$ Baylor St. Luke's Hospital
}

Corresponding author: Esmeralda Celia Marginean; email: celia.marginean@bcm.edu

\section{Abstract}

Gastric cancer (GC) is the fifth most common type of cancer and the third leading cause of cancer-related deaths in the world. GC is a heterogeneous disease with diverse molecular and histological subtypes, which, may have different therapeutic implications. Using sophisticated molecular technologies and analyses, 3 separate groups recently provided genetic and epigenetic molecular classifications of GC: Singapore-Duke, The Cancer Genome Atlas project (TCGA) and the Asian Cancer Research Group (ACRG). These molecular classifications are time-consuming, complex, and costly and require sophisticated molecular technologies, which, prevent their widespread availability and use in clinical practice. Therefore, several practical pathological classifications were developed using immunohistochemical stains, fluorescent in situ hybridization and/or polymerase chain reaction (PCR), which, approximate, albeit not perfectly, the molecular classifications of GC. These are simple algorithms, less expensive and easy to reproduce in any pathology laboratory. Both molecular and histological classifications should be used for choosing adequate therapy and stratification purposes in clinical trials. This is a review of current molecular and pathological classification of GC.

Keywords: gastric cancer, pathology classification, molecular classification

\section{Introduction}

Gastric cancer (GC) is a major global health problem and the third leading cause of cancer related deaths worldwide. The incidence is highest in Asia (with over half of all GC cases globally diagnosed in East Asia), Eastern Europe, and South America with comparatively lower rates in Africa, North America, and Europe. The overall survival for resected gastric cancer patients is poor; for US population, 5-year survival is 
$64 \%$ (local), $28.2 \%$ (regional) and 5.3\% (distant metastases), with overall 5-year survival of $32.4 \%$ (1).

The disappointing survival rates are due to the limited treatment options and tumor heterogeneity, especially at the molecular level, with limited targetable biomarkers. Surgery is the $1^{\text {st }}$ line treatment for GC, producing an overall survival rate of 60 $70 \%$ for early-stage disease. High GC incidence nations such as Japan and Korea now implement routine screening for early detection when the disease is highly curable. In many less developed countries, however, GC is mostly detected only in its advanced stages, precluding curative surgical resection, and necessitating systemic treatment. The low efficacy of current therapies results in advanced or metastatic GC having a low survival rate of 5-20\%, and a particularly poor prognosis for peritoneal GC recurrence (2).

\section{Pathological Classification of Gastric Cancer}

Historically, GC was classified morphologically by Lauren in 1965 in 2 main catego- ries: intestinal type and diffuse type (Fig.1) (3). This classification is still widely accepted by pathologists and clinicians in contemporary practice. Intestinal and diffuse GC exhibits numerous differences in pathology, epidemiology and etiology. Intestinal type is more common in older males, frequently associated with Helicobacter pylori infection, which, leads to gastric atrophy, intestinal metaplasia, low-grade dysplasia, high-grade dysplasia, and intestinal type adenocarcinoma, in a stepwise progression, known as Correa cascade (4). Diffuse type tends to occur in younger patients, mostly females and may occur in familial clusters. Histologically, these tumors lack expression of adhesion molecules and typically show an infiltrative, poorly differentiated, poorly cohesive appearance. Somatic and germline mutations in a number of genes contribute to diffuse type of GC: E-cadherin (CDH1), TP53, RHOA, CTNN1A, and CMTM2. Approximately $1-3 \%$ of all GC are due to hereditary diffuse gastric cancer (HDGC), with $30-40 \%$ of those associated with germline mutations in $\mathrm{CDH} 1$ (5).
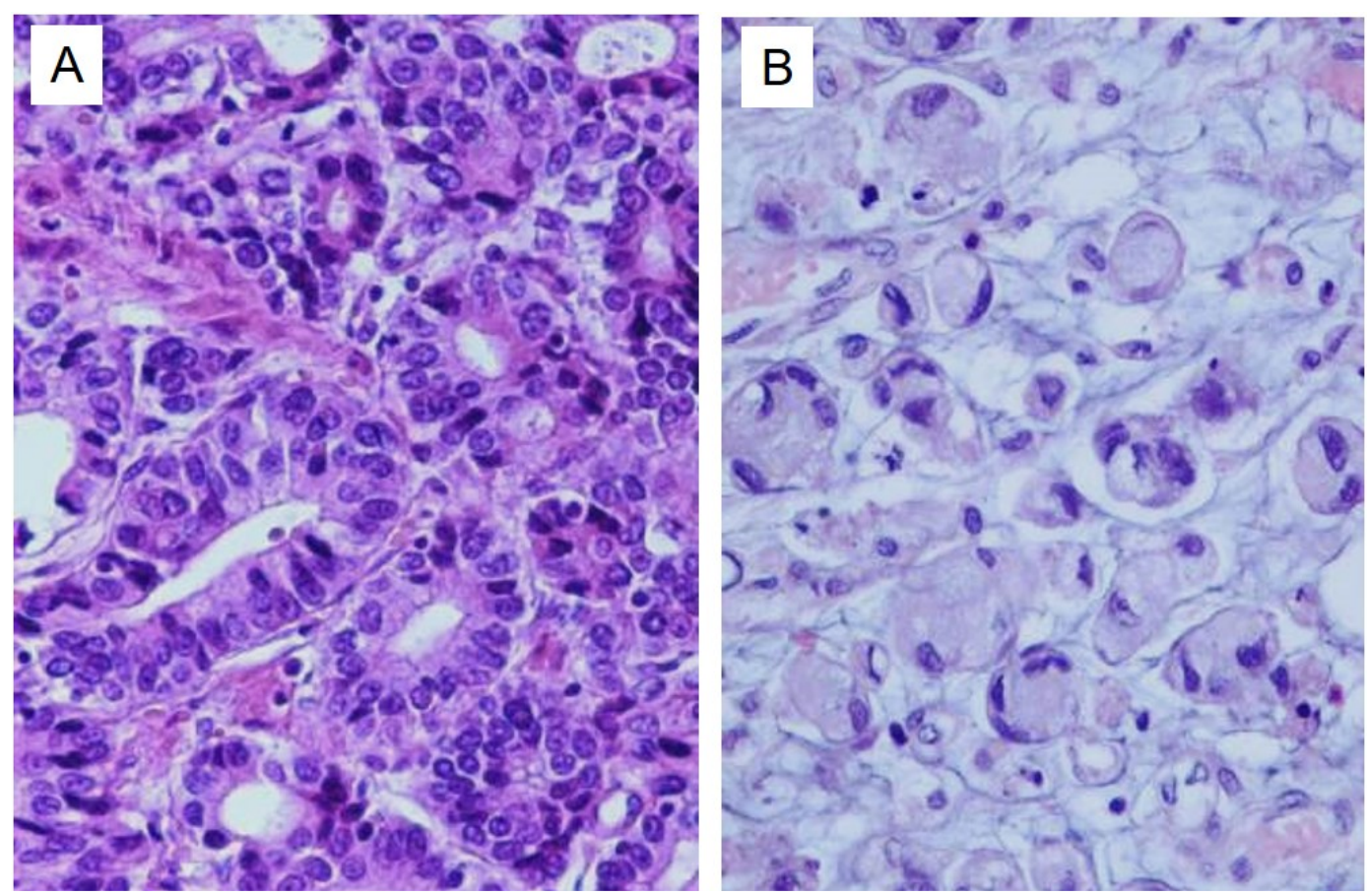

Fig. 1. Lauren Classification of Gastric Cancer (1965) 
Table 1. Evolution of Histological Classification of Gastric Malignant Epithelial Tumors

\begin{tabular}{|c|c|c|c|}
\hline Lauren 1965 & WHO 2000 & WHO 2010 & WHO 2019 \\
\hline Intestinal & $\begin{array}{l}\text { Papillary } \\
\text { Tubular (grade 1-3) }\end{array}$ & $\begin{array}{l}\text { Papillary } \\
\text { Tubular, well and } \\
\text { moderately } \\
\text { differentiated }\end{array}$ & $\begin{array}{l}\text { Papillary } \\
\text { Tubular, well and } \\
\text { moderately differentiated }\end{array}$ \\
\hline $\begin{array}{l}\text { Indeterminate } \\
\text { Indeterminate/ } \\
\text { intestinal/diffuse }\end{array}$ & Mucinous & $\begin{array}{l}\text { Tubular, poorly } \\
\text { differentiated (solid) } \\
\text { Mucinous }\end{array}$ & $\begin{array}{l}\text { Tubular, poorly } \\
\text { differentiated (solid) } \\
\text { Mucinous }\end{array}$ \\
\hline Diffuse & $\begin{array}{l}\text { Diffuse (signet ring } \\
\text { carcinoma) }\end{array}$ & $\begin{array}{l}\text { Poorly cohesive } \\
\text { carcinoma } \\
\text { (including signet ring } \\
\text { carcinoma and other } \\
\text { variants) }\end{array}$ & $\begin{array}{l}\text { Poorly cohesive carcinoma NOS } \\
\text { Signet ring carcinoma }\end{array}$ \\
\hline $\begin{array}{l}\text { Mixed } \\
\text { adenocarcinoma }\end{array}$ & $\begin{array}{l}\text { Mixed } \\
\text { adenocarcinoma }\end{array}$ & $\begin{array}{l}\text { Mixed } \\
\text { adenocarcinoma }\end{array}$ & Mixed adenocarcinoma \\
\hline Not defined & $\begin{array}{l}\text { Histological } \\
\text { variants of } \\
\text { carcinoma: } \\
\text { Adenosquamous } \\
\text { carcinoma } \\
\text { Squamous cell } \\
\text { carcinoma } \\
\text { Undifferentiated } \\
\text { carcinoma } \\
\text { Small cell carcinoma } \\
\text { Others } \\
\text { Carcinoid }\end{array}$ & $\begin{array}{l}\text { Histological } \\
\text { variants of } \\
\text { carcinoma: } \\
\text { Adenosquamous } \\
\text { carcinoma } \\
\text { Squamous cell } \\
\text { carcinoma } \\
\text { Undifferentiated } \\
\text { carcinoma } \\
\text { Carcinoma with } \\
\text { lymphoid stroma } \\
\text { (medullary) } \\
\text { Hepatoid carcinoma } \\
\text { Others } \\
\text { Neuroendocrine } \\
\text { neoplasms: } \\
\text { Neuroendocrine } \\
\text { tumors (NET) } \\
\text { NET G1 } \\
\text { (carcinoid) } \\
\text { NET G2 } \\
\text { Neuroendocrine } \\
\text { carcinoma (NEC) } \\
\text { Large cell } \\
\text { Small cell } \\
\text { Mixed adeno- } \\
\text { neuroendocrine } \\
\text { carcinoma (MANEC) } \\
\text { ECL and serotonin } \\
\text { producing NET } \\
\text { Gastrin producing } \\
\text { NET (gastrinoma) }\end{array}$ & $\begin{array}{l}\text { Adenocarcinoma: } \\
\text { Carcinoma with } \\
\text { lymphoid stroma } \\
\text { Hepatoid carcinoma } \\
\text { Paneth cell carcinoma } \\
\text { Adenocarcinoma } \\
\text { with enteroblastic differentiation } \\
\text { Parietal cell adenocarcinoma } \\
\text { Mucoepidermoid carcinoma } \\
\text { Micropapillary adenocarcinoma } \\
\\
\text { Adenosquamous carcinoma } \\
\text { Squamous cell carcinoma } \\
\text { Undifferentiated carcinoma NOS: } \\
\text { Large cell carcinoma with } \\
\text { rhabdoid phenotype } \\
\text { Pleomorphic carcinoma } \\
\text { Sarcomatoid carcinoma } \\
\text { Carcinoma with osteoclast like } \\
\text { giant cells } \\
\text { Gastroblastoma } \\
\text { Neuroendocrine tumor NOS } \\
\text { NET grade } 1 \\
\text { NET grade } 2 \\
\text { NET grade } 3 \\
\text { Gastrinoma NOS } \\
\text { Somatostatinoma NOS } \\
\text { Enterochromaffin-cell carcinoid } \\
\text { ECL-cell malignant carcinoid } \\
\text { Neuroendocrine carcinoma NOS } \\
\text { Large cell } \\
\text { Small cell } \\
\text { Mixed neuroendocrine-non } \\
\text { neuroendocrine neoplasm } \\
\text { (MiNEN) }\end{array}$ \\
\hline
\end{tabular}


The World Health Organization (WHO) Classification of Tumors of the Digestive System, published in 2000 based on the views of the Working Group meeting in 1999 , classified gastric carcinoma into adenocarcinoma, intestinal and diffuse type, and several subtypes: papillary, tubular and mucinous adenocarcinoma, signet ring cell, adenosquamous, squamous, small cell and undifferentiated carcinoma. This classification had several shortcomings: it was purely descriptive, with little clinical utility; it did not address several subtypes, like mixed diffuse and intestinal type carcinomas, poorly differentiated carcinomas without signet ring cells; and finally, it included small cell carcinomas in the same category with adenocarcinomas, only carcinoid tumors being considered a separate category (Table 1). All these histologic types were recognized by American Joint Committee on Cancer (AJCC) staging manual 5th edition (1997) and staged using the same staging system, except for carcinoid tumors.

Some of the shortcomings were addressed by the subsequent edition of WHO book, published 10 years later. To the previously described categories of papillary, tubular and mucinous adenocarcinoma, a new category was added: poorly cohesive carcinoma, which, included signet ring carcinoma and other variants, as well as mixed adenocarcinoma. Maybe the most important change was separation of neuroendocrine neoplasms as a separate category, which, includes neuroendocrine tumors (NET) grade 1 and grade 2, neuroendocrine carcinoma (NEC), large cell and small cell type, mixed adenoneuroendocrine carcinoma (MANEC), and NET producing gastrin and serotonin (Table 1). A list of the most common genetic alterations found in intestinal and diffuse types of gastric cancer were included in this edition.

In the meantime, the AJCC staging manual went through two new editions: 6th edition (2002) and 7th edition (2010). Both editions still included and staged small cell carcinoma together with the other epithelial carcinomas, while carcinoid tumors were a separate category. Finally, the 7th edition created a single separate staging category for well differentiated NET and well differentiated NEC of stomach, small intestine, colorectal and duodenal ampulla.

The latest edition of the WHO book (5th edition), published in 2019, based on the debates of the WHO Classification of Tumors Editorial Board meeting in 2018, significantly expanded the classification of malignant epithelial tumors. Adenocarcinoma was classified in several subtypes: tubular, parietal cell, mixed, papillary NOS, micropapillary NOS, mucoepidermoid, mucinous, signet ring cell, poorly cohesive, medullary carcinoma with lymphoid stroma and hepatoid adenocarcinoma. Undifferentiated carcinoma has several subtypes: large cell carcinoma with rhabdoid phenotype, pleomorphic carcinoma, sarcomatoid carcinoma, carcinoma with osteoclast-like giant cells. Neuroendocrine neoplasms were classified in NET NOS, with the following subtypes: NET grade 1, grade 2, grade 3, gastrinoma, somatostatinoma, enterochromaffin cell carcinoid (ECL) and ECL carcinoid, malignant. Neuroendocrine carcinoma NOS continues to remain a separate category, with large cell and small cell subtypes. MANEC has been renamed as mixed neuroendocrine-non neuroendocrine neoplasm (MiNEN). Gastroblastoma was added as a separate category. Probably the most significant addition was the inclusion of the new genetic and epigenetic molecular classifications proposed by The Cancer Genome Atlas Research Network (TCGA) and the Asian Cancer Research Group (ACRG). The latest edition of the AJCC staging manual (8th edition) published in 2017 and the College of American Pathologists (CAP) Cancer Protocol Templates, which, are frequently updated, created separate pathologic staging systems for well differentiated neuroendocrine tumors, separate for each 
gastrointestinal site, while NEC and MiNEN are staged using the same template as carcinomas.

\section{Molecular Classification of Gastric Cancer}

Gastric cancer is a highly heterogeneous disease from molecular point of view, in dire need of specific biomarker-driven cancer therapies. There have been several efforts to perform large-scale molecular profiling and classification of GC, summarized in Table 2.

\section{Familial gastric cancer}

About $10 \%$ of GC show familial clustering, but only approximately $1-3 \%$ of GC are associated with inherited gastric cancer predisposition syndromes, such as hereditary diffuse gastric carcinoma (HDGC), familial adenomatosis polyposis syndrome (FAP), hereditary nonpolyposis colorectal carcinoma (HNP CC/Lynch syndrome), juvenile polyposis syndrome, Peutz-Jeghers syndrome, Li-Fraumeni syndrome and gastric hyperplastic polyposis syndrome (6).

HDGC is an autosomal dominant disorder with high penetrance. Approximately 30$40 \%$ of patients have a germline mutation in the tumor suppressor E-cadherin gene $(\mathrm{CDH} 1)$. The inactivation of the second allele through mutation, methylation and/or loss of heterozygosity eventually triggers the development of gastric cancer (7-9). Underexpression or complete loss of E-cadherin is associated with epithelial-mesenchymal transition (EMT), a poor prognostic indicator. The presence of this mutation confers over $80 \%$ lifetime risk of gastric carcinoma, and prophylactic total gastrectomy after confirmation of $\mathrm{CDH} 1$ mutation is the only procedure that increases survival (10). Additionally, annual mammography and breast MRI starting at age of 35 are recommended for women with HDGC, due to their increased risk of lobular breast cancer (11). The histologic phenotype of HDGC corres- ponds to diffuse type in Lauren classification, or poorly cohesive type with signet ring cells in WHO fifth edition. Relatively characteristic to HDCG in early stage is a pagetoidlike spread of signet ring carcinoma cells (signet ring carcinoma in situ), which, has not been reported in the sporadic form of signet ring carcinoma (12). CDH1 genetic testing of blood for germline mutation should be performed in Clinical Laboratory Improvement Amendments (CLIA)-certified molecular diagnostic laboratories in USA, or laboratories with expertise in $\mathrm{CDH} 1$ gene analysis.

Beyond hereditary GC, the more common sporadic form of diffuse type GC has also been associated with E-cadherin loss, either through somatic mutation or promoter hypermethylation. Recently, a pair of studies published in Nature Genetics expands our understanding of diffuse type $\mathrm{GC}$ by describing novel recurrent mutations of $R H O A$, encoding the small GTPase RhoA, in $14.3 \%-25.3 \%$ of patients $(13,14)$. These findings implicate RHOA as a novel candidate driver for diffuse gastric cancer.

\section{Human epidermal growth factor re- ceptor 2 (HER2)}

HER2 is a member of the epidermal growth factor receptor (EGFR) family, which, includes ErbB2/HER2, ErbB3/HER3, and ErbB4/HER4. All of them are oncogenic drivers and were described initially in lung cancer, breast cancer and glioblastoma, and later in colon cancer, bladder, ovary, cervix, stomach and gastroesophageal junction (GEJ) cancers (15). Inhibitors of these receptors have been associated with the most successful results of targeted cancer therapies to date, including antibody therapeutics (trastuzumab and cetuximab), small molecule tyrosine kinase inhibitors (osimertinib, erlotinib, afatinib, gefitinib, lapatinib, mobocertinib and tucatinib) and the newly developed drug conjugates (trastuzumab emtansine and trastuzumab deruxtecan) $(16,17)$. 
Table 2. Current Molecular Classifications of GC

\begin{tabular}{|c|c|c|c|c|c|}
\hline \multicolumn{6}{|c|}{ Current molecular classifications of GC } \\
\hline \multirow{2}{*}{$\begin{array}{l}\text { The Cancer } \\
\text { Genome } \\
\text { Atlas } \\
\text { (TCGA) } \\
2014\end{array}$} & \multirow[b]{2}{*}{$\begin{array}{c}\text { EBV } \\
\text { EBV-CIMP } \\
\text { PIK3CA } \\
\text { mutations } \\
\text { PD-L1/PD- } \\
\text { L2 } \\
\text { expression } \\
\end{array}$} & \multirow{2}{*}{$\begin{array}{c}\text { MSI } \\
\text { MLH1 promoter } \\
\text { hypermethylation } \\
\text { Hypermutated } \\
\text { Gastric CIMP }\end{array}$} & \multirow[b]{2}{*}{$\begin{array}{c}\text { GS } \\
\text { CDH1, RHOA } \\
\text { mutations } \\
\text { Diffuse } \\
\text { histology } \\
\text { Younger } \\
\text { females } \\
\end{array}$} & CIN & \\
\hline & & & & $\begin{array}{l}\text { TP53 mutations } \\
\text { Intestinal } \\
\text { histology }\end{array}$ & \\
\hline \multirow{2}{*}{$\begin{array}{l}\text { Singapore- } \\
\text { Duke } \\
2013\end{array}$} & & Mesenchymal & Proliferative & Metabolic \\
\hline & & & $\begin{array}{c}\text { Low level of } \\
\text { CDH1 } \\
\text { Low TP53 } \\
\text { Diffuse } \\
\text { histology } \\
\text { PIK3CA-mTOR } \\
\text { inhibitors }\end{array}$ & $\begin{array}{l}\text { High TP53 } \\
\text { Intestinal } \\
\text { histology }\end{array}$ & $\begin{array}{l}\text { Low TP53 } \\
\text { No histologic } \\
\text { correlation } \\
\text { 5-FU+surgery }\end{array}$ \\
\hline $\begin{array}{l}\text { Asian } \\
\text { Cancer } \\
\text { Research } \\
\text { Group } \\
\text { (ACRG) }\end{array}$ & & MSI & MSS/EMT & MSS/TP53- & MSS/TP53+ \\
\hline \multirow[t]{4}{*}{2015} & & $\begin{array}{c}\text { ARID1A, KRAS, } \\
\text { PIK3CA }\end{array}$ & Loss CDH1 & $\begin{array}{c}\text { TP53 } \\
\text { mutations, } \\
\text { ERB2, EGFR, } \\
\text { MDM2, GATA6 }\end{array}$ & $\begin{array}{l}\text { EBV, APC, } \\
\text { ARID1A, } \\
\text { KRAS, } \\
\text { PIK3CA, } \\
\text { SMAD4 }\end{array}$ \\
\hline & & \multirow{3}{*}{$\begin{array}{l}\text { Intestinal histology } \\
\text { Antrum } \\
\text { Early stage } \\
\text { Best prognosis }\end{array}$} & \multirow{3}{*}{$\begin{array}{c}\text { Diffuse } \\
\text { histology } \\
\text { Younger age } \\
\text { Worst } \\
\text { prognosis }\end{array}$} & $\begin{array}{l}\text { Intestinal } \\
\text { histology }\end{array}$ & $\begin{array}{l}\text { Intestinal } \\
\text { histology }\end{array}$ \\
\hline & & & & Male & Male \\
\hline & & & & $\begin{array}{c}\text { Intermediate } \\
\text { prognosis }\end{array}$ & $\begin{array}{l}\text { Intermediate } \\
\text { prognosis }\end{array}$ \\
\hline
\end{tabular}

HER2 gene amplification and overexpression of the HER2 protein by immunohistochemistry was discovered in gastric carcinoma in 1986 (18). The rate of HER2 overexpression in gastric adenocarcinoma ranges from as low as $4 \%$ to as high as $53 \%$ (19-23), with an average of $20 \%$ in a large meta-analysis (23). HER2 overexpression is more often noted in intestinal type carcinoma adenocarcinomas located at proximal stomach, cardia and gastroesophageal junction. A large phase 3 international clinical trial (ToGA trial) showed that the humanized monoclonal antibody against HER2, trastuzumab (Herceptin), when combined with chemotherapy (capecitabine or 5-FU and cisplatin) prolongs overall survival and progression free survival in patients with HER2 positive advanced gastric carcinoma (24). Based on this study, in 2010, trastuzumab was approved by FDA in USA, Health Canada and by the European Commission for the treatment of HER2 positive metastatic gastric or GEJ adenocarcinoma in combination with standard chemotherapy, for patients who have not received prior treatment for metastatic disease.

In the ToGA trial, HER2 was assessed by immunohistochemistry and scored as 0 , $1+$ (negative), $2+$ (equivocal) and $3+$ (positive). The tumors showing equivocal $(2+)$ staining were confirmed by fluorescent in situ hybridization (FISH), which, if showed amplification of HER2 were considered 
positive and patients were eligible for therapy with trastuzumab (Fig.2A). HER2 scoring criteria in GC are slightly different from breast cancer, requiring either complete, basal lateral or lateral membranous staining, unlike breast HER2 interpretation which, requires completely circumferential staining. Another difference between breast and gastric cancer HER2 interpretations is the amount of tumor cells required: small clusters composed of minimum 5 tumor cells in biopsies of gastric or GEJ cancer, and $10 \%$ of tumor cells in resection specimens respectively, are adequate for evaluation (Fig. 2B).

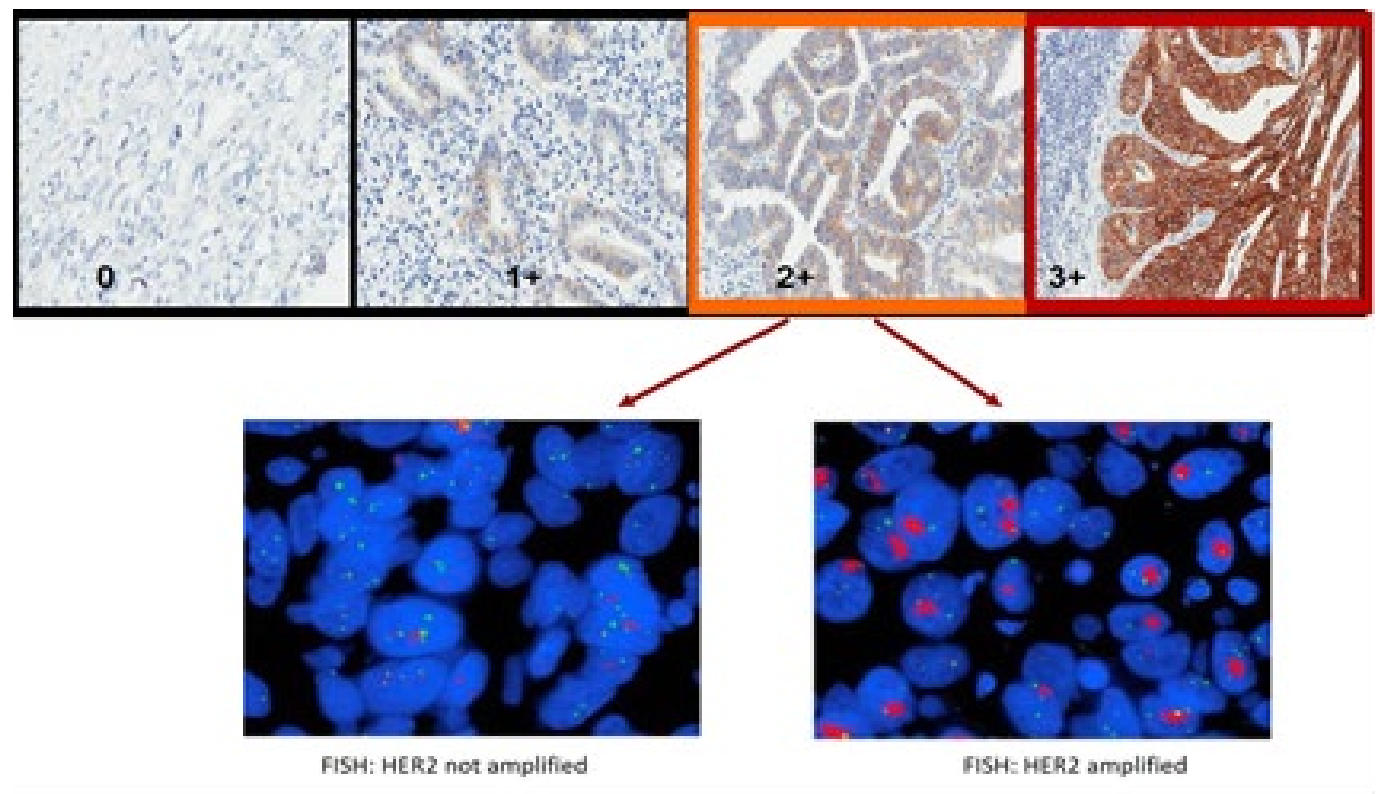

A.

FISH: HER2 not amplified

FISH: HER2 amplified

\begin{tabular}{|c|c|c|c|c|}
\hline & Score & $\begin{array}{l}\text { Surgical specimen } \\
\text { - staining pattern }\end{array}$ & $\begin{array}{l}\text { Biopsy specimen } \\
\text { - staining pattern }\end{array}$ & $\begin{array}{l}\text { HER2 } \\
\text { overexpression } \\
\text { assessment }\end{array}$ \\
\hline 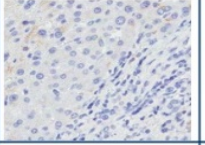 & 0 & $\begin{array}{c}\text { No reactivity or } \\
\text { membranous reactivity in } \\
\text { any tumor cells }\end{array}$ & $\begin{array}{l}\text { No reactivity or no membranous } \\
\text { reactivity in any tumor cell }\end{array}$ & Negative \\
\hline 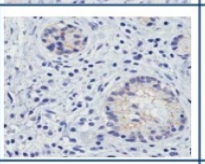 & $1+$ & $\begin{array}{l}\text { Faint / barely perceptible } \\
\text { membranous reactivity } \\
\text { in } \geq \mathbf{1 0 \%} \text { of tumor cells }\end{array}$ & $\begin{array}{c}\text { Tumour cell cluster with a faint / } \\
\text { barely perceptible membranous } \\
\text { reactivity irrespective of } \\
\text { percentage of tumour cells } \\
\text { stained }\end{array}$ & Negative \\
\hline 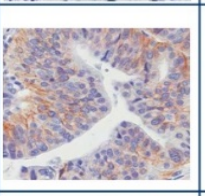 & $2+$ & $\begin{array}{l}\text { Weak to moderate } \\
\text { complete, basolateral or } \\
\text { lateral membranous } \\
\text { reactivity in } \geq \mathbf{1 0} \% \text { of } \\
\text { tumour } \\
\text { cells }\end{array}$ & $\begin{array}{l}\text { Tumor cell cluster with weak to } \\
\text { moderate complete, basolateral } \\
\text { or lateral membranous reactivity } \\
\text { irrespective of percentage of } \\
\text { tumor cells stained }\end{array}$ & Equivocal \\
\hline 40 & $3+$ & $\begin{array}{l}\text { Strong complete, } \\
\text { basolateral or lateral } \\
\text { membranous reactivity in } \\
\geq \mathbf{1 0} \% \text { of tumor cells }\end{array}$ & $\begin{array}{c}\text { Tumor cell cluster with a strong } \\
\text { complete, basolateral or lateral } \\
\text { membranous reactivity } \\
\text { irrespective of percentage of } \\
\text { tumor cells stained }\end{array}$ & Positive \\
\hline
\end{tabular}

Fig. 2. HER2 testing in gastric cancer: A. Immunohistochemical staining is interpreted as negative (score 0 and $1+$ ), equivocal (score $2+$ ) and positive (score $3+$ ). Tumors with equivocal $(2+)$ staining should be confirmed by fluorescent in situ hybridization (FISH), which, analyzes the ratio between HER2 gene copy number and chromosome 17 centromere. HER2/CEP17 ratio $>2$ in over 20 tumor cells is considered HER2 amplified. B. HER2 scoring guidelines in gastric cancer in biopsy and resection specimens, according to the ToGA trial. 
Current recommendations are to use immunohistochemistry as the initial testing methodology, with FISH or silver in situ hybridization (SISH) used only to retest equivocal $(2+)$ cases (25). There is a strong demonstrated concordance in HER2 expression between biopsy and resection specimens (26), therefore, most of the time there is no need to re-test HER2 on the resection.

Therefore, HER2 has been established as the first, and, so far, the only approved molecular biomarker available for gastric cancer patients in clinical practice and recommended by CAP (27), and trastuzumab is the first FDA approved molecular targeted agent for the treatment of gastric cancer.

\section{Singapore-Duke Classification of Gastric Cancer}

The gastric cancer project 2008 Singapore cohort (28) was one of the first major projects that tried to identify the key oncogenic pathways deranged in gastric cancer, associated with a significant impact on survival. Using gene expression signatures, an in-silico strategy to map patterns of oncogenic pathway activation in 301 primary gastric cancers was developed. Also, 3 oncogenic pathways, subsequently validated in gastric cancer cell lines, were described: proliferation/stem cell, NFkappaB, and Wnt/beta catenin.

A follow-up study of the Singapore cohort conducted by Lei et al. (29) compared gene expression patterns among 248 GC from Singaporean patients and identified 3 major subtypes:

1. proliferative - characterized by high genomic instability, TP53 mutations and DNA hypomethylation

2. metabolic - more sensitive to 5fluorouracil (5-FU) than other subtypes

3. mesenchymal - with features of cancer stem cells; cell lines of this subtype are particularly sensitive to inhibitors of phosphatidylinositol-3-kinase/mammalian target of rapamycin (PI3K/mTOR) pathway.
The Cancer Genome Atlas (TCGA) Gastric Cancer Molecular Classification

In 2014, as part of TCGA project, the genome and proteome of gastric cancer were extensively characterized in order to uncover molecular subtypes and identify dysregulated pathways and potential therapeutic targets (30). Fresh frozen tissue and matched germline DNA samples of 295 primary gastric adenocarcinoma not previously treated with chemotherapy or radiation therapy were studied by using 6 different molecular platforms (array-based somatic copy number analysis, whole exon sequencing, array-based DNA methylation profiling, mRNA sequencing, micro-RNA sequencing and reverse-phase protein array), with $77 \%$ of tumors tested with all 6 platforms.

Analysis of data created a decision tree which, separated the gastric cancer in 4 distinct subtypes, with the following characteristics:

1. Epstein-Barr virus (EBV; $9 \%$ of patients)-characterized by EBV positivity, these tumors had higher prevalence of DNA promoter hypermethylation, frequent PIK3CA, ARID1A and BCOR mutations, with rare TP53 mutations. All EBV positive tumors exhibited extreme $\mathrm{CpG}$ island methylator phenotype (CIMP), distinct from that in the MSI subtype. They displayed CDKN2A (p16) promoter hypermethylation but lacked the $\mathrm{MLH} 1$ hypermethylation characteristic of MSI associated CIMP. Mutations in PIK3CA, ERBB3, ERBB2 and EGFR were noted. EBV gastric cancers were mostly in males and located in the fundus or body and had prolonged survival (31).

2. Microsatellite high instability (MSI; $22 \%$ of patients)-included tumors with elevated mutation rates and hypermethylation (including hypermethylation MLH1 promoter). Absent from this group were BRAF mutations, commonly seen in MSI colorectal cancer. These patients tended to be older 
females and morphologically, the gastric cancer was intestinal type.

3. Genomically stable (GS; $50 \%$ of patients) - the tumor has had a low mutational burden and low somatic copy number aberration. Clinically, these group demonstrated more aggressive disease, with $73 \%$ of tumors occurring in younger patients, showing diffuse histology, with $\mathrm{CDH} 1$ mutations and RHOA mutations.

4. Chromosomal instability (CIN; $20 \%$ of patients) - the tumors show high somatic copy number aberrations, aneuploidy and focal amplification of receptor tyrosine kinases (RTKs) (i.e., EGFR, ERBB2 and ERBB3), and, VEGFA, MET, TP53, APC mutations.

In theory, amplifications of RTKs are amenable to blockade by therapeutics (RTK inhibitors); VEGFA can be targeted by the VEGFR2-targeting antibody (ramucirumab), and amplifications of cell cycle mediators (CCN E1, CCN D1 and CDK 6), are amenable to therapy by inhibition of cyclin-dependent kinases (32). These tumors are more frequent at the gastroesophageal junction/cardia and show intestinal morphology.

\section{Asian Cancer Research Group (ACRG) Gastric Cancer Molecular Classification}

The ACRG expanded upon the TCGA analysis by performing additional expression analyses and correlated the results to their institutions high-quality clinical outcomes, which, included recurrence and survival. In its initial study, whole genome sequencing was performed in 49 patients, and recurrent somatic mutations were identified (33). A year later, ACRG published the results of gene expression profiling, genome-wide copy number microarrays and targeted gene sequencing on an additional 251 patients, for a total of 300 primary GC tumor specimens. Tissue was obtained at the time of total or subtotal gastrectomy from Samsung Medical Center in Korea. All patients were chemotherapy naïve. Long follow-up was available (median 86.4 months). Based on a decision tree, similar with TCGA group, they identified four molecular subtypes that were associated with survival and recurrence patterns after surgery (34):

1. Microsatellite high instability (MSI; $23 \%$ of patients) - This subtype had the best prognosis, and more than half of patients were diagnosed with early-stage cancer (stage I-II), similar with TCGA MSI subset. MSI subtype was associated with the presence of hypermutation, with mutations in several genes: K-ras (23.3\%), the PI3KPTEN-mTOR pathway (42\%), ALK (16.3\%) and ARID1A (44.2\%).

2. Microsatellite stable/ epithelial mesenchymal type (MSS/EMT; $15 \%$ of patients) - The EMT subtype had a lower number of mutation events compared to the other MSS groups. These tumors were mostly present in young patients (median age 53 years), showed diffuse type histology, presented at advanced stages (stage III-IV) and were more commonly located in the antrum and body. This subtype had the worst overall prognosis and recurrence free survival. Although $80 \%$ of MSS/EMT tumors showed diffuse morphology, overall, only $27 \%$ of all diffuse gastric cancers in this study were part of this subgroup, which, suggests that more than $70 \%$ of diffuse gastric cancer had a better prognosis. This group is similar with the GS group of TCGA. EMT and MSI exhibited a mutually exclusive pattern.

3. MSS/TP53+ (26.3\% of patients) these tumors showed intact TP53, frequent EBV infections and mutations in APC, ARID1A, KRAS, PIK3CA, SMAD4 genes.

4. MSS/TP53- (35.7\% of patients) these tumors showed functional loss of TP53, with the highest prevalence of TP53 mutations (60\%) and a low frequency of other mutations: ERBB2, EGFR, MDM2, GATA6. TP53 is the most mutated gene in gastric cancer. TP53 signature was measured in this study based on 2-genes: CDKN1A (p21) and MDM2. Intact TP53 in 
group 3 means high signature score (TP53+) whereas functional loss of TP53 means low signature score in group 4 (TP53-). TP53 activity signature correlated with the TP53 mutation status.

As opposed to the TCGA analysis, ACRG group run a survival analysis on their cohort of patients, and they validated on three separate independent cohorts: Samsung Medical Center $2 \quad(n=277)$; Singapore cohort $(n=200)$; TCGA cohort $(n=205)$. They noticed that the gastric cancer subtypes were statistically correlated to the overall survival in all four cohorts, either individual or combined datasets. The best overall survival was present in the MSI group both in each individual cohort, and in the combined cohorts, while the MSS/EMT subtype had the worst overall survival. The pattern of recurrence for each GC subtype was also investigated as an exploratory analysis using clinical data from the ACRG and Samsung Medical Center cohort. The MSS/EMT group had a higher risk of recurrence compared to the MSI group (63\% versus $23 \%$ ). Additionally, they observed that the first site of recurrence was related to subtypes as follows: MSS/EMT subtype had a higher percentage of peritoneal seeding versus all other subtypes (64\% versus $23 \%$; also, the $\mathrm{MSI}$ and MSS/TP53 subgroups showed a high percentage of metastases limited to the liver $23 \%$ and $21 \%$ respectively) versus the MSS/EMT and MSS/TP53+ subtypes (4.6\% and $8 \%$ respectively). When compared with the other reported molecular subtypes (TCGA and Singapore cohorts), they noticed similarities, such as tumors with MSI in both ACRG and TCGA subtypes, and between the GS, EBV and CIN TCGA subtypes and the ACRG subtypes MSS/EMT, MSS/TP53+ and MSS/TP53 respectively (Table 2). However, they noticed several differences in terms of cohort, molecular mechanism, driver gene and prognoses association. For example, tumors classified as TCGA CIN subtype were present across all ACRG subtypes. Also, the diffuse type histology was lower in the TCGA cohort (24\% in TCGA versus $45 \%$ in ACRG), with most diffuse type cases present in the TCGA GS group, but only $27 \%$ cases present in the ACRG MSS/EMT subtype. This is suggestive of less heterogeneity present in the diffuse subtype in the TCGA cohort. Also, CDH1 mutations, frequent in the TCGA GS subtype (37\%), were infrequent in the ACRG MSS/EMT subtype (2.8\%). Additionally, RHOA mutations were more prevalent in the MSS/TP53-and MSS/TP53+ then in the TCGA GS group. All of these differences suggest that the TCGA GS type is not equivalent to the ACRG MSS/EMT subtype. In general, the Singapore and TCGA subtypes are similar with the notable exception that there is no equivalent subtype that corresponds to the ACRG MSS/TP53+ or MSS/TP53-, making the ACRG classification rather unique. These molecular signatures of gastric cancer have important clinical implications for molecular screening and targeted therapy agents development. However, a significant hurdle for the use of molecular signatures in clinical practice is the cost and availability of these tests.

Several intrepid pathologists have tried to come up with clinically feasible and costeffective strategies and developed varied subtyping algorithms using immunohistochemical stains and/or FISH, tying to approximate the molecular subtypes of GC. Some of these algorithms are described in the section below.

Development of a practical immunohistochemical algorithm for the identification of molecular subtypes of gastric cancer

In 2016, Kim et al. had described a tenstain panel, using EBER, mismatch repair (MMR) proteins (MLH1, PMS2, MSH2, and MSH6), receptor tyrosine kinases (HER2, EGFR, and MET), PTEN, and p53 protein. This panel is extensive, with several immunostains (i.e., EGFR, MET, PTEN) that are not routinely utilized in surgical pathology labs (35). 


\section{A. Biomarker-based classification (Setia et. al)}

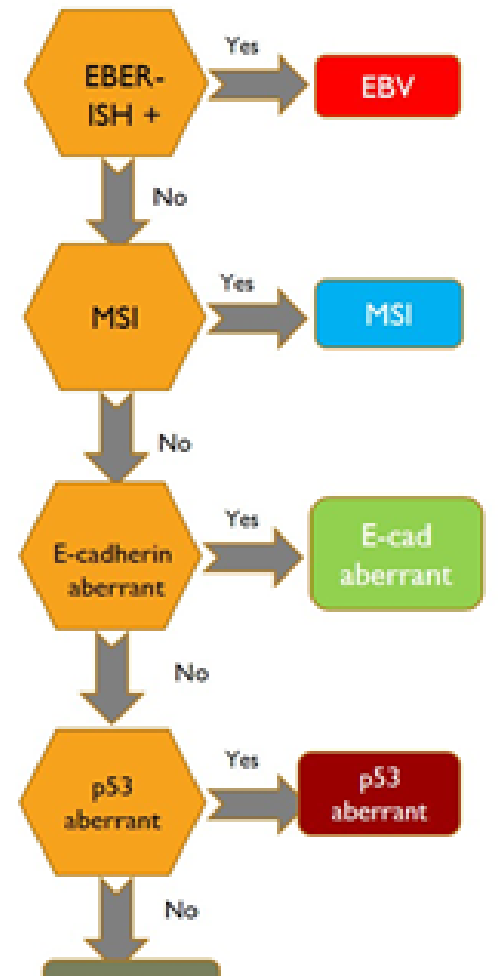

B. Approximation of TCGA subtypes
C.Approximation of ACRG subtypes

p53 normal

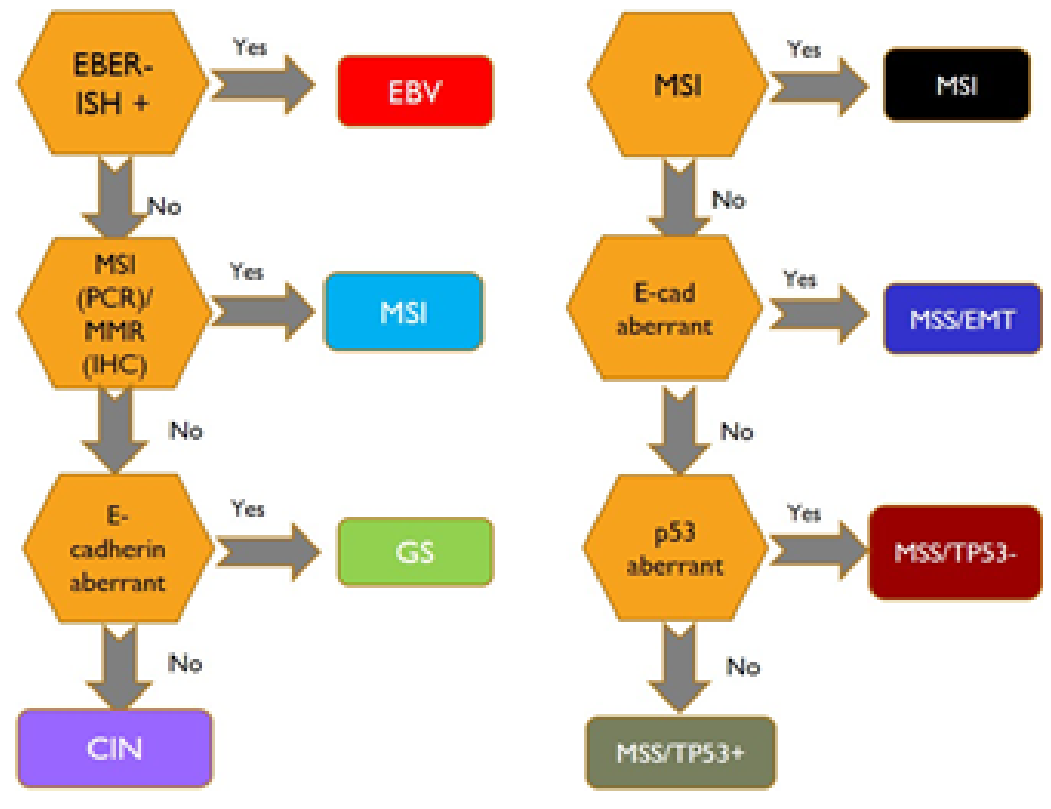

Fig. 3. Practical pathological algorithms that approximate molecular classification of gastric cancer. A. Integrated classification. B. TCGA classification. EBER in situ hybridization separates EBV group; immunohistochemical stains for MMR or PCR separate MSI group; E-cadherin immunohistochemical stain separate genomically stable (GS) group and the remainder are chromosomal instability (CIN) group. C. ACRG classification. Immunohistochemical stains for MMR or PCR separate MSI group; aberrant E-cadherin stain (complete loss or faint cytoplasmic staining) separate MSS/EMT group; aberrant p53 immunostain (strong staining in $>70 \%$ of tumor cells) separates the MSS/TP53- group; the remainder group with wild-type (normal) p53 staining pattern is MSS/TP53+ group.

This was a large study conducted on 438 consecutive patients with advanced gastric adenocarcinoma from South Korea. The biomarkers were performed on whole sections slides - a clear advantage over the subsequent studies, the majority performed on tissue microarrays (TMA) blocks, which, include a very small tumor sample (cores of 1 or $2 \mathrm{~mm}$ ).

The same year, Setia et. al group proposed a 5-tier classification algorithm, based on 14 biomarkers, which, included EBER in situ hybridization and immunohistochemical stains for mismatch repair proteins (MLH1, PMS2, MSH2 and MSH6), E-cadherin, PD-L1, MUC 2, CDX2, CD10,
MUC 5AC, MUC6 and HER2 (36). These biomarkers were performed on TMA blocks constructed from 146 primary gastric cancers. This team described 5 different groups of GC (Fig. 3A):

1. EBER positive $(5 \%)$ - these tumors showed a prominent lymphoid infiltrate, and they were associated with PD-L1, which, suggests a potential role for immunotherapy with anti-PD1/PD-L1 monoclonal antibodies. EBV cluster showed a trend towards better survival, however not statistically significant.

2. MMR deficient $(16 \%)$ - which, correlates with the MSI group from both TCGA and ACRG classifications 
3. E-cadherin aberrant (21\%) - most of the tumors in this group were diffuse type (90\%). This group correlates with the genomically stable group of the TCGA, the MSS/ EMT subgroup of the ACRG and the mesenchymal group of the Singapore classification.

4. Aberrant TP53 expression (51\%) - further subclassified into intestinal type (33\%, based on MUC2 and/or CD10 expression), gastric type (32\%, MUC5AC and/or MUC6 positive) and normal type (20\%, CD10, MUC2, MUC5AC and MUC6 negative). The subclassification based on MUC and CD10 immunostains has no clinical impact and is purely morphological.

This group was similar to the CIN group of TCGA, the proliferative subtype of Singapore classification and MSS/TP53- of ACRG. The majority (81\%) were intestinal type, and a trend of HER2 expression was noted. Gastric cancer with aberrant TP53 expression may benefit from targeted therapy with receptor tyrosine kinase blockers (HER2, EGFR, VEGFR, c-MET), cell cycle (CCNE1, CCND1, CDK6) inhibitors and fibroblast growth factor receptor 2 inhibitors.

5. Normal TP53 expression (wild-type)corresponding to the metabolic subtype in Singapore classification, is highly sensitive to 5-FU therapy.

These groups are not mutually exclusive; however, they approximate well the recently described genetic classifications of gastric cancer. More importantly, they are easy to perform in most pathology laboratories and they use common immunohistochemical stains and FISH.

Several other authors have attempted to develop a practical algorithm to approximate the molecular classification. In 2019, a Canadian group used 5 commonly used immunohistochemical stains (p53 and MMR proteins MLH1, MSH 2, MSH 6 and PMS 2) and EBV in situ hybridization on TMA blocks constructed from 107 gastric cancers (37). They created a subtyping algorithm based on TCGA classification, using a series of dichotomizing steps:

1. EBV-CIMP tumors, identified by EBER positivity

2. MSI tumors, based on MMR immunostains

\section{CIN}

4. GS

The latter 2 groups were based simply on histology (diffuse versus intestinal/mixed types), using the rationale that GS tumors were enriched for diffuse histology in the TCGA classification; HER2 and diffuse histology were mutually exclusive in their cohort. The logic behind this approach was that addition of any other markers would make the subtyping cumbersome and difficult to implement in clinical practice.

The Canadian team also approximated ACRG molecular subtypes based on MMR, which, identifies the MSI subtype; and the microsatellite stable (MSS) tumors were subclassified further using p53, which, identifies the MSS/TP53- and MSS/TP53+ groups. My personal opinion is that this method is elegant and easy to implement in clinical practice; also, it is cost effective and can be performed in any pathology lab.

A large Korean research consortium developed and validated another simplified algorithm as a surrogate for molecular subtypes of gastric cancer, using EBV in situ hybridization, MSI PCR testing and immunohistochemical stains for E-cadherin and p53 on 894 gastric cancers (38). Five successive groups were described: EBV, $\mathrm{MSI}$, E-Cadherin loss (EBV negative/ microsatellite stable/ EMT- like) group, aberrant p53 (EBV negative/ microsatellite stable/ EMT- like/ TP53-) group and normal p53 (EBV negative/ microsatellite stable/ EMT- like/ TP53+) group.

Studies on immunophenotypic classification of GC are currently ongoing. At present, the immunohistochemical definition of GC subtypes, especially related to the TP53 and E-cadherin genes expression, is still unsettled. In general, according to the criteria 
of Ando et. al (39), aberrant TP53 expression in tumor cells is demonstrated by strong and diffuse staining of more than $70 \%$ of the tumor cells nuclei. A completely negative staining or patchy and weak staining is an indication of a wild type TP53 gene. A complete loss of membranous staining or a faint cytoplasmic reactivity of Ecadherin is indicative of an aberrant expression of this gene. A complete membranous or a heterogeneous cytoplasmic/ membranous staining pattern are considered normal E-cadherin staining patterns (36).

\section{Therapeutic considerations}

A better understanding of the various molecular characteristics of gastric cancer is critical for diagnostic assessment, prognostic evaluation, and the development of new therapeutic strategies for this aggressive disease. In GC, heterogeneity is present not only between different patients but, also, significantly, within the same patient where it can be both intra- and inter-temporal and spatial and temporal.

At present, there are several targeted agents FDA-approved for the treatment of gastric cancer: trastuzumab, ramucirumab, pembrolizumab, bemarituzumab, larotrectinib and entrectinib.

Based on the ToGA trial (24), trastuzumab was FDA approved in 2010 for patients with HER2 positive tumors for first line treatment in combination with chemotherapy. Based on the REGARD trial (40), ramucirumab (a VEFGR2 inhibitor) was FDA approved in 2014 as a second line treatment in patients with unresectable or metastatic disease following treatment with a fluoropyrimidine- or platinum-containing therapy. Ramucirumab is the first biological treatment given that has demonstrated a survival benefit as a single drug in patients with advanced gastric or GEJ adenocarcinoma progressing after first-line chemotherapy. Based on the seminal study by Le at. al (41), pembrolizumab (an anti-PD-1) was approved in 2017 for the treatment of cancer patients with microsatellite instability-high (MSI-H) markers or mismatch repair deficient (dMMR) markers. For gastric cancers expressing PD-L1 and negative for HER2, pembrolizumab was approved in 2017 as a third line of treatment in patients with disease progression after two or more systemic therapies, including fluoropyrimidineand platinum-containing chemotherapy and, if appropriate, HER2/neu-targeted therapy $(42,43)$. PD-L1 testing as a companion diagnostic test (PD-L1 IHC 22C3 pharmDx) for pembrolizumab, is an immunohistochemical stain performed on formalin-fixed embedded tissue and is scored assessing immunoreactivity of tumor cells and immune cells, using the CPS scoring method (44, 45). The CPS was defined as the total number of tumor cells and immune cells (including lymphocytes and macrophages) stained with PD-L1 divided by the number of all viable tumor cells, then multiplied by 100 (https://www.captodayonline.com/scoringgastric-gej-cancers-pd-I1-expression/). According to the KEYNOTE 059 study, CPS score $\geq 1$ predicts response to the PD-1 inhibitors $(46,47)$.

Additionally, pembrolizumab was also approved for solid tumors showing high tumor burden (TMB) who had progressed following prior treatment and lacked alternative treatment options. Based on data from the KEYNOTE-158 study, high TMB was defined as $\geq 10$ mutations/Mb by next generation sequencing (NGS), regardless of MSI status (48). TMB is broadly defined as the number of somatic mutations per megabase of analyzed genomic sequences. TMB predicts response to immunotherapy both in MSI-H and MSS populations, and is independent of the level of PD-L1 expression, suggesting a potential role of TMB to identify additional subgroups of patients who may benefit from immunotherapy (49). In GC, the TMB cutoff may vary, from 14 mutations/Mb (50) to 10 mutations/Mb (51) or 8.8 in another study 
(52), but it is always associated with better response to immunotherapy.

Based on 3 separate studies (53) in 2018, FDA granted accelerated approval to larotrectinib for adult and pediatric patients with solid tumors that have a neurotrophic receptor tyrosine kinase (NTRK) gene fusion without a known acquired resistance mutation, that are either metastatic or where surgical resection is likely to result in severe morbidity, and who have no satisfactory alternative treatments or whose cancer has progressed following treatment. This was the second tissue-agnostic FDA approval for the treatment of cancer after the pembrolizumab approval described above. Identification of positive NTRK gene fusion status may be determined in local laboratories using NGS or fluorescence in situ hybridization (FISH). Current ESMO recommendations include pan-TRK immunohistochemistry as an approved method to screen for NTRK gene fusions (54). However, NTRK fusions are extremely rare in GC in Asian patients (55), and one German study found none in 438 Caucasian patients with GC (56), therefore testing for NTRK in GC may not be that useful.

Entrectinib was the third FDA-approved tissue-agnostic drug based on the presence of a biomarker (NRTK) across different types of tumours. Like larotrectinib, entrectinib is an oral NTRK, ROS1, and ALK inhibitor and appears to be effective against a range of NTRK fusion-positive tumor types. The drug has shown clinically meaningful and durable responses in NTRK-positive tumors. However, similar to larotrectinib, it is so rare in GC that its testing is not cost effective.

More recently, based on the FIGHT study (57), in April 2021, FDA granted breakthrough therapy designation to bemarituzumab for use in combination with modified FOLFOX6 chemotherapy as firstline treatment in metastatic or locally advanced GC or GEJ adenocarcinoma fibroblast growth factor receptor $2 b$ (FGFR2b) positive and HER2-negative.

\section{Summary}

Pathologists play a crucial role in evaluating the histology and the biomarker results and establishing the appropriate biomarker detection methods. Delineating MSI-H/dMMR tumors and determining HER2 positivity, are straightforward and can be performed in any pathology lab using routine immunohistochemical stains and/or in situ hybridization methods and polymerase chain reaction (PCR) tools. Currently, CAP recommends testing only for HER2 in patients with inoperable, locally advanced, recurrent or metastatic gastric and GEJ adenocarcinomas for whom trastuzumab therapy is being considered, while NCCN guidelines recommend additional universal testing for MSI/MMR by PCR/IHC in all newly diagnosed patients. PD-L1 testing, using an approved FDA companion diagnostic test, may be required for locally advanced, recurrent or metastatic gastric and GEJ adenocarcinomas for whom therapy with PD1 inhibitors is considered.

The latest advances in molecular methods have increased our understanding of GC biology and led to the development of new comprehensive molecular classifications. The TCGA project was a landmark effort that provided a molecular classification of GC, which, may serve as a valuable adjunct to histopathology. As a result of the TCGA database presence, 4 subtypes with distinct clinical and molecular features of GC were described: EBV, MSI, GS and CIN. However, the TCGA subtypes did not show significant correlations with overall and disease-free survivals (OS and DFS), and this may be due to several factors: the duration of follow-up, the heterogeneity of patients; ethnicities, the geographical distribution and the treatment received. The ACRG group expanded upon the TCGA database analysis by performing additional expre- 
ssion analyses and correlated the results to their institutions outcomes, which, included both data on survival and recurrence. They also described four subtypes of gastric cancer (MSI, MSS/EMT, MSS/TP53+ and MSS/TP53-), which, unlike the TCGA group classification, were associated with survival and specific recurrence patterns after surgery.

These molecular classifications are time-consuming, extremely complex, costly and require sophisticated molecular technologies, which, prevent their widespread availability and use in clinical practice. Therefore, development of practical, easy to use and cost-effective classification systems for predicting prognosis or treatment response is needed. Immunohistochemical, in situ hybridization and/or PCR ancillary tests are excellent surrogates that approximate the molecular classification.

Currently, several algorithms for phenotyping gastric cancer using immunohistochemical markers and in situ hybridization have been published. Most of the studies done for this purpose employed TMAs, which, sample only a small portion of tumors. A simple and practical algorithm uses EBV in situ hybridization in order to identify EBER, MMR protein expression (using MLH1, MSH2, MSH6 and PMS2), E- cadherin and p53 immunohistochemical stains (Fig. 3B, C) as surrogate markers for the TCGA and ACRG subgroups. Although they do not match perfectly with the molecular subgroups, all these biomarkers are easily available in any pathology laboratory and represent a cost effective, practical and easy to use algorithm which, approximates genomic profiling and could be an alternative in guiding targeted therapies. They can be used in addition to the already established and approved tests for HER2, PD-L1 and MSI/MMR.

A good communication between the medical oncologists and the pathologists is a must as it facilitates effective tissue collection, proper tissue triage and appropriate histopathological and biomarker testing. Providing a detailed clinical history to the pathologists including information about the clinical stage, the resectability, and the therapy envisioned, may guide the nature of biomarkers that should be tested for. This is especially useful when the amount of tissue is limited, for example, in a mucosal biopsy, where sequential testing for single biomarkers may exhaust the tissue. In these situations, a comprehensive genomic profiling via an NGS validated platform is recommended to identify HER2, MSI/MMR, PD-L1, TMB and NTRK mutations.

\author{
Abbreviations: \\ GC - gastric cancer \\ TCGA - the Cancer Genome Atlas project \\ ACRG - Asian Cancer Research Group \\ $\mathrm{PCR}$ - polymerase chain reaction \\ US - United States \\ HDGC - hereditary diffuse gastric cancer \\ WHO - World Health Organization \\ AJCC - American Joint Committee on Cancer \\ NET - neuroendocrine tumors \\ NEC - neuroendocrine carcinoma \\ MANEC - mixed adeno-neuroendocrine carcinoma \\ NOS - not otherwise specified \\ $\mathrm{ECL}$ - enterochromaffin cell carcinoid \\ MiNEN - mixed neuroendocrine-non neuroendocrine neoplasm \\ CAP - College of American Pathologists \\ FAP - familial adenomatous polyposis syndrome
}


HNP CC - hereditary nonpolyposis colorectal carcinoma

EMT - epithelial-mesenchymal transition

CLIA - Clinical Laboratory Improvement Amendments

GEJ - gastroesophageal junction

FDA - The United States Food and Drug Administration

SISH - silver in situ hybridization

5-FU - 5-fluorouracil

$\mathrm{PI} 3 \mathrm{~K} / \mathrm{mTOR}$ - phosphatidylinositol-3-kinase/mammalian target of rapamycin

$\mathrm{MSI}$ - microsatellite high instability

GS - genomically stable

CIN - chromosomal instability

RTK - receptor tyrosine kinases

EBV - Epstein-Barr virus

MSS - Microsatellite stable

EMT - Epithelial mesenchymal transition

MMR - mismatch repair

EBER - Epstein-Barr virus-encoded small RNAs

FISH - fluorescence in situ hybridization

TMA - tissue microarray

MSI-H microsatellite instability-high

dMMR - mismatch repair deficient

CPS scoring - combined positive score

PD-1/PDL-1 - programmed cell death protein 1/ programmed cell death-ligand 1

TMB - high tumor burden

NTRK - neurotrophic receptor tyrosine kinase

VEGFA - vascular endothelial growth factor $A$

VEGFR - vascular endothelial growth factor receptor

NGS - next generation sequencing

ESMO - European Society of Medical Oncology

FGFR2b - fibroblast growth factor receptor $2 b$

OS - overall survival

DFS - disease free survival

Statements: None.

Previous publication: We declare that this paper was not published nor was submitted to be reviewed for publication in another journal.

Conflict of interest: We declare having no competing interests associated with this publication.

Funding Sources: This research did not receive any specific grant from funding agencies in the public, commercial, or not-for-profit sector.

\section{References}

1. Jim MA, Pinheiro PS, Carreira H, Espey DK, Wiggins CL, Weir HK. Stomach cancer survival in the United States by race and stage (2001-2009): Findings from the CONCORD-2 study. Cancer. Dec 15 2017;123 Suppl 24(Suppl 24):4994-5013.

2. Chang HR, Nam S, Lee J, Kim JH, Jung HR, Park HS et al. Systematic approach identifies RHOA as a potential biomarker therapeutic target for Asian gastric cancer. Oncotarget. Dec 6 2016;7(49):81435-81451. 
3. Lauren P. The two histological main types of gastric carcinoma: diffuse and so-called intestinal-type carcinoma. An attempt at a histo-clinical classification. Acta Pathol Microbiol Scand. 1965;64:31-49.

4. Correa P, Piazuelo MB. The gastric precancerous cascade. J Dig Dis. Jan 2012;13(1):2-9.

5. Shi J, Qu Y-P, Hou P. Pathogenetic mechanisms in gastric cancer. World journal of gastroenterology. 2014;20(38):13804-13819.

6. Oliveira C, Suriano G, Ferreira P, Canedo P, Kaurah P, Mateus R et al. Genetic screening for familial gastric cancer. Hered Cancer Clin Pract. May 15 2004;2(2):51-64.

7. Pharoah PD, Guilford P, Caldas C. Incidence of gastric cancer and breast cancer in CDH1 (E-cadherin) mutation carriers from hereditary diffuse gastric cancer families. Gastroenterology. Dec 2001;121(6):1348-53.

8. Barber M, Murrell A, Ito Y, Maia AT, Hyland S, Oliveira C, et al. Mechanisms and sequelae of E-cadherin silencing in hereditary diffuse gastric cancer. J Pathol. Nov 2008;216(3):295-306. doi:10.1002/path.2426

9. Oliveira C, Sousa S, Pinheiro H, Karam R, Boredira-Carrico R, Senz J, et al. Quantification of epigenetic and genetic 2nd hits in $\mathrm{CDH} 1$ during hereditary diffuse gastric cancer syndrome progression. Gastroenterology. Jun 2009;136(7):2137-48.

10. Oliveira C, Bordin MC, Grehan N, Huntsman D, Suriana G, Machado JC, et al. Screening E-cadherin in gastric cancer families reveals germline mutations only in hereditary diffuse gastric cancer kindred. Hum Mutat. May 2002;19(5):510-7.

12. Oliveira C, Moreira H, Seruca R, de Oliveira MC, Carneiro F. Role of pathology in the identification of hereditary diffuse gastric cancer: report of a Portuguese family. Virchows Arch. Feb 2005;446(2):181-4.

13. Kakiuchi M, Nishizawa T, Ueda H, Gotoh K, Tanaka A, Hayashi A, et al. Recurrent gain-of-function mutations of RHOA in diffuse-type gastric carcinoma. Nat Genet. Jun 2014;46(6):583-7.

14. Wang K, Yuen ST, Xu J, Lee SP, Yan HN, Shi ST, et al. Whole-genome sequencing and comprehensive molecular profiling identify new driver mutations in gastric cancer. Nat Genet. Jun 2014;46(6):573-82.

15. Kaur A, Dasanu CA. Targeting the HER2 pathway for the therapy of lower esophageal and gastric adenocarcinoma. Expert Opin Pharmacother. Nov 2011;12(16):2493-503.

16. Lemmon MA, Schlessinger J, Ferguson KM. The EGFR family: not so prototypical receptor tyrosine kinases. Cold Spring Harb Perspect Biol. Apr 1 2014;6(4):a020768.

17. Ferraro E, Drago JZ, Modi S. Implementing antibody-drug conjugates (ADCs) in HER2-positive breast cancer: state of the art and future directions. Breast Cancer Res. Aug 11 2021;23(1):84.

18. Sakai K, Mori S, Kawamoto T, Taniguchi S, Kobori O, Morioka Y, et al. Expression of epidermal growth factor receptors on normal human gastric epithelia and gastric carcinomas. J Natl Cancer Inst. Nov 1986;77(5):1047-52.

19. Abrahão-Machado LF, Jácome AA, Wohnrath DR, dos Santos JS, Carneseca EC, Tavares GF, et al. HER2 in gastric cancer: comparative analysis of three different antibodies using whole-tissue sections and tissue microarrays. World J Gastroenterol. Oct 14 2013;19(38):6438-46.

20. Abrahao-Machado LF, Scapulatempo-Neto C. HER2 testing in gastric cancer: An update. World J Gastroenterol. May 2016;22(19):4619-25.

21. Kunz PL, Mojtahed A, Fisher GA Ford JM, Chang DT, Balise RR, et al. HER2 expression in gastric and gastroesophageal junction adenocarcinoma in a US population: clinicopathologic analysis with proposed approach to HER2 assessment. Appl Immunohistochem Mol Morphol. Jan 2012;20(1):13-24.

22. Shan L, Ying J, Lu N. HER2 expression and relevant clinicopathological features in gastric and gastroesophageal junction adenocarcinoma in a Chinese population. Diagn Pathol. May 9 2013;8:76. 
23. Maresch J, Schoppmann SF, Thallinger CM, Zielinski CC, Hejna M. Her-2/neu gene amplification and overexpression in stomach and esophageal adenocarcinoma: from pathology to treatment. Crit Rev Oncol Hematol. Jun 2012;82(3):310-22.

24. Van Cutsem E, Kang Y, Chung H, Shen L, Sawaki A, Lordickj F, et al. Efficacy results from the ToGA trial: A phase III study of trastuzumab added to standard chemotherapy (CT) in first-line human epidermal growth factor receptor 2 (HER2)-positive advanced gastric cancer (GC). Journal of Clinical Oncology. 2009/06/20 2009;27(18_suppl): LBA4509-LBA4509.

25. Dominguez C, Rosa M, George TB, Pimiento J, Lauwers GY, Coppola D. Evaluation of Expression of Human Epidermal Growth Factor Receptor 2 (HER2) in Gastric and Gastroesophageal Junction Adenocarcinoma Using IHC and Dual-ISH. Anticancer Res. Jan 2018;38(1):367-372.

26. Wang T, Hsieh ET, Henry P, Hanna W, Streutker CJ, Grin A. Matched biopsy and resection specimens of gastric and gastroesophageal adenocarcinoma show high concordance in HER2 status. Hum Pathol. May 2014;45(5):970-5.

27. Bartley AN, Washington MK, Colasacco C, Ventru CB, Ismaila N, Benso AB, et al. HER2 Testing and Clinical Decision Making in Gastroesophageal Adenocarcinoma: Guideline From the College of American Pathologists, American Society for Clinical Pathology, and the American Society of Clinical Oncology. J Clin Oncol. Feb 2017;35(4):446-464.

28. Ooi $\mathrm{CH}$, Ivanova $\mathrm{T}, \mathrm{Wu} \mathrm{J}$, Lee $\mathrm{M}$, Tan IB, Tao $\mathrm{J}$ et al. Oncogenic pathway combinations predict clinical prognosis in gastric cancer. PLoS Genet. Oct 2009;5(10):e1000676.

29. Lei Z, Tan IB, Das K, Deng N, Zouridis H, Pattison S, et al. Identification of molecular subtypes of gastric cancer with different responses to PI3-kinase inhibitors and 5-fluorouracil. Gastroenterology. Sep 2013;145(3):554-65.

30. Cancer Genome Atlas Research Network. Comprehensive molecular characterization of gastric adenocarcinoma. Nature. Sep 11 2014;513(7517):202-9.

31. Camargo MC, Kim WH, Chiaravalli AM, Kim KM, Corvalan AH, Matsuo K, et al. Improved survival of gastric cancer with tumour Epstein-Barr virus positivity: an international pooled analysis. Gut. Feb 2014;63(2):236-43.

32. Morishita A, Gong J, Masaki T. Targeting receptor tyrosine kinases in gastric cancer. World J Gastroenterol. Apr 28 2014;20(16):4536-45.

33. Wong SS, Kim KM, Ting JC, Yu K, Fu J, Liu S, et al. Genomic landscape and genetic heterogeneity in gastric adenocarcinoma revealed by whole-genome sequencing. Nat Commun. Nov 19 2014;5:5477.

34. Cristescu R, Lee J, Nebozhyn M, Kim KM, Ting JC, Wong SW, et al. Molecular analysis of gastric cancer identifies subtypes associated with distinct clinical outcomes. Nat Med. May 2015;21(5):449-56.

35. Kim HS, Shin SJ, Beom SH, Jung M, Choi YY, Son T, et al. Comprehensive expression profiles of gastric cancer molecular subtypes by immunohistochemistry: implications for individualized therapy. Oncotarget. Jul 12 2016;7(28):44608-44620.

36. Setia N, Agoston AT, Han HS, Mullen JT, Duda DG, Clark JW, et al. A protein and mRNA expression-based classification of gastric cancer. Mod Pathol. Jul 2016;29(7):772-84.

37. Yoon JY, Sy K, Brezden-Masley C, Streutker CJ. Histo- and immunohistochemistry-based estimation of the TCGA and ACRG molecular subtypes for gastric carcinoma and their prognostic significance: A single-institution study. PLoS One. 2019;14(12):e0224812.

38. Koh J, Lee KW, Nam SK, Seo AN, Kim JW, Park DJ, et al. Development and Validation of an Easy-toImplement, Practical Algorithm for the Identification of Molecular Subtypes of Gastric Cancer: Prognostic and Therapeutic Implications. Oncologist. Dec 2019;24(12):e1321-e1330.

39. Ando K, Oki E, Saeki H, Yan Z, Tsuda Y, Hidaka G, et al. Discrimination of p53 immunohistochemistrypositive tumors by its staining pattern in gastric cancer. Cancer Med. Jan 2015;4(1):75-83.

40. Fuchs CS, Tomasek J, Yong CJ, Dumitru F, Passalacqua R, Goswami C, et al. Ramucirumab monotherapy for previously treated advanced gastric or gastro-oesophageal junction adenocarcinoma (REGARD): an international, randomised, multicentre, placebo-controlled, phase 3 trial. Lancet. Jan 4 2014;383(9911):31-39. 
41. Le DT, Uram JN, Wang H, Bartlett BT, Kmeberling H, Eyring AD, et al. PD-1 Blockade in Tumors with Mismatch-Repair Deficiency. N Engl J Med. Jun 25 2015;372(26):2509-20. doi:10.1056/NEJMoa1500596

42. Fashoyin-Aje L, Donoghue M, Chen H, He K, Veeraraghavan J, Goldberg KB, et al. FDA Approval Summary: Pembrolizumab for Recurrent Locally Advanced or Metastatic Gastric or Gastroesophageal Junction Adenocarcinoma Expressing PD-L1. Oncologist. Jan 2019;24(1):103-109.

43. Yu Y. Molecular classification and precision therapy of cancer: immune checkpoint inhibitors. Front Med. Apr 2018;12(2):229-235.

44. Pereira MA, Ramos M, Dias AR, Ribeiro R, Cardili L, Zilberstein B, et al. Scoring systems for PD-L1 expression and their prognostic impact in patients with resectable gastric cancer. Virchows Arch. Jun 2021;478(6):1039-1048.

45. Kulangara K, Zhang N, Corigliano E, Guerrero L, Waldroup S, Jaiswal D, et al. Clinical Utility of the Combined Positive Score for Programmed Death Ligand-1 Expression and the Approval of Pembrolizumab for Treatment of Gastric Cancer. Arch Pathol Lab Med. Mar 2019;143(3):330-337.

46. Cho J, Lee J, Bang H, Kim ST, Park SH, An JY, et al. Programmed cell death-ligand 1 expression predicts survival in patients with gastric carcinoma with microsatellite instability. Oncotarget. Feb 21 2017;8(8):13320-13328.

47. Fuchs CS, Doi T, Jang RW, Muro K, Satoh T, Machado M, et al. Safety and Efficacy of Pembrolizumab Monotherapy in Patients With Previously Treated Advanced Gastric and Gastroesophageal Junction Cancer: Phase 2 Clinical KEYNOTE-059 Trial. JAMA Oncol. May 10 2018;4(5):e180013.

48. Marabelle A, Fakih M, Lopez J, Shah M, Frommer RS, Nakagawa K, et al. Association of tumour mutational burden with outcomes in patients with advanced solid tumours treated with pembrolizumab: prospective biomarker analysis of the multicohort, open-label, phase 2 KEYNOTE-158 study. Lancet Oncol. Oct 2020;21(10):1353-1365.

49. Sha D, Jin Z, Budczies J, Kluck K, Stenzinger A, Sinicrope FA. Tumor Mutational Burden as a Predictive Biomarker in Solid Tumors. Cancer discovery. 2020;10(12):1808-1825.

50. Kim J, Kim B, Kang SY, Heo YJ, Park SH, Kim ST, et al. Tumor Mutational Burden Determined by Panel Sequencing Predicts Survival After Immunotherapy in Patients With Advanced Gastric Cancer. Frontiers in oncology. 2020;10:314-314.

51. Shitara K, Özgüroğlu M, Bang YJ, Bartolomeo MD, Manadala M, Ryu MH, et al. Molecular determinants of clinical outcomes with pembrolizumab versus paclitaxel in a randomized, open-label, phase III trial in patients with gastroesophageal adenocarcinoma. Ann Oncol. Sep 2021;32(9):1127-1136.

52. Samstein RM, Lee $\mathrm{CH}$, Shoushtari AN, Hellman MD, Shen R, Janjigian YY, et al. Tumor mutational load predicts survival after immunotherapy across multiple cancer types. Nat Genet. Feb 2019;51(2):202-206.

53. Drilon A, Laetsch TW, Kummar S, DuBois SG, Lassen UN, Demetri GD, et al. Efficacy of Larotrectinib in TRK Fusion-Positive Cancers in Adults and Children. New England Journal of Medicine. 2018/02/22 2018;378(8):731-739.

54. Marchiò C, Scaltriti M, Ladanyi M, lafrate AJ, Bibeau F, Dietel M, et al. ESMO recommendations on the standard methods to detect NTRK fusions in daily practice and clinical research. Ann Oncol. Sep 1 2019;30(9):1417-1427.

55. Shinozaki-Ushiku A, Ishikawa S, Komura D, Seto Y, Aburatani H, Ushiku T. The first case of gastric carcinoma with NTRK rearrangement: identification of a novel ATP1B-NTRK1 fusion. Gastric Cancer. Sep 2020;23(5):944-947.

56. Arnold MA, Swanson BJ, Crowder CD, Franker WL, Lam-Himlin D, Singhi AD, et al. Colesevelam and colestipol: novel medication resins in the gastrointestinal tract. Am J Surg Pathol. Nov 2014;38(11):1530-7.

57. Catenacci DV, Tesfaye A, Tejani M, Cheung E, Eisenber P, Scott AJ, Eng C, et al. Bemarituzumab with modified FOLFOX6 for advanced FGFR2-positive gastroesophageal cancer: FIGHT Phase III study design. Future Oncol. Jun 2019;15(18):2073-2082. 